\title{
A Brief Analysis on the Theoretical Study of Rural Leisure Sports Devel- opment of Coupled Ecological and Industrial Chain
}

\author{
Chenggen Peng*
}

Agricultural University of Hunan Institute of sports and Art, China

\begin{abstract}
With increasing life pressure and shrinking leisure area due to the integral improvement of urbanization level in recent years, people gradually start to explore the possibility of leisure sports in rural area. This thesis has identified the concept of coupled ecological and industrial chain, and performed mechanism analysis of dynamic effect, and then further unfolded the development of rural leisure sports under ecological industry coupled mode. The result of research has confirmed that ecological industry coupling can optimize the integral effect of rural leisure sports. Through discussion and analysis, this thesis hopes to provide certain reference to the promotion of peasant sport program and the development of leisure sports in rural area.
\end{abstract}

Keywords: Coupling, development, ecological chain and industry, rural leisure sports.

\section{INTRODUCTION}

With the increasing urbanization level of China in recent years, urban living environment is deteriorating day by day with expanding population and environment pollution. As available facilities and public occasions for physical exercises and leisure, such as parks and greenbelts, are being decreased in concrete jungle, people thirst for some places for leisure and exercise. While in other perspectives, with increasing burden and accelerated rhythm of life and work, people are eager to seek for natural occasions for relaxation. Especially with the building process of new socialist countryside, cultural business starts to flourish in many rural areas [1-3]. As rural areas are featured by small population intensity and excellent living environment, they have advantageous conditions to build leisure sport projects under the context of harmonious socialist society. This can not only promote the infrastructure construction of rural areas, but also can boost the implementation of peasant physical training projects and create advantageous conditions for the development of leisure sports in countryside.

\section{IMPLICATION AND CONTENT OF RURAL LEI- SURE SPORTS}

\subsection{Implication}

Leisure sport is not only a kind of cultural activity passing down over a few thousand years, but also a sport activity containing profound historical and cultural deposits. In recent years, rural leisure sport has gradually attracted the attention of the large rural population. Country and city, the two important geographic concepts in China, will classify people's leisure sports into urban and rural leisure sport. The participators of rural leisure sports are mainly the urban citizens living in the city and seeking for leisure in countryside, and the rural populations living in the country. Therefore, rural leisure sports only subjects the world "rural" to geographic concept. This kind of project mainly takes advantage of the geographical conditions of a vast rural area, for example, mountain, river, field, lake and so on, to mobilize rural and urban populations to actively participate in leisure sports, such as ball games, fishing leisure, chess and card entertainment, walking and sightseeing, climbing, drifting, hunting and so on [4-6].

\section{CONTENT}

As China owns a vast rural area and abundant resources, the rural leisure sports in countryside can contain various contents, including rural tour, leisure outdoor fitness activities, rural community leisure sports and so on. Rural tour mainly refers to a great many of leisure sports in various rural facilities in the vast rural area, such as interesting rural home inns, holiday village, leisure farm, ecological garden, fishing leisure center, water sports center, hunting ground and so on; leisure outdoor fitness activities refer to the nature-based uprising sports held in outdoors and natural environment; wonderful rural community leisure sports mainly refer to the leisure sports held in various rural sports fields and facilities and participated by rural community residents.

For example, Qingdao has abundant coastal leisure sport resources. The development of coastal leisure sport products and services should form a complete system including offshore leisure projects, coastal leisure projects, health and fitness projects, island leisure projects and mountain leisure projects, as shown in Table $\mathbf{1}$.

\section{INFLUENCE OF RURAL LEISURE SPORTS ON URBAN CONSTRUCTION}

One of essential parts for the leisure activities of people is leisure sport. To achieve the goal of leisure, people have 
Table 1. Qingdao coastal leisure sport products and service items.

\begin{tabular}{|c|c|c|}
\hline Project & Resources & Products and Services \\
\hline \hline Offshore leisure project & Offshore sport center & sailing boat, surfing, motorboat and so on \\
\hline Coastal leisure project & Bathing beach & beach ball, sand carving, swimming and so on \\
\hline Health and fitness project & Coastal sanatorium & sand therapy, water therapy, mud therapy and so on \\
\hline Island leisure project & Island & fishing, field survival and so on \\
\hline Mountain leisure project & Laoshan Mountain & Sailing boat, sailboard, beach ball and so on \\
\hline Competition project & Beach and offshore activity center \\
\hline
\end{tabular}

made great efforts to develop leisure sports to enhance physical health and embody the comprehensive development. Due to well-equipped facilities and advanced technologies in the city, it is convenient for people to take urban leisure sports, which not only meets the requirements of people to attend leisure sports, but also promotes the development of urban economy, culture and education. As an uprising industry, leisure sports have a promising future and are the stimulus to urban economic development.

Promote the integration of leisure sport industry with tourist leisure industry and cultural leisure industry, exert the initiative of enterprise under the support and guidance of government, and establish the long-term docking mechanism of leisure sport industry, tourism and cultural industry through demand complementarity, resources sharing, industry association and value chain extension, as shown in Fig. (1).

For example, Qingdao city located in Shandong province is evaluated as one of "Top 10 Leisure Cities" in China due to its excellent urban environment, high economic level and abundant leisure sport resources and culture. As some Olympic items were held in Qingdao, Qing citizens were filled by enthusiasm toward leisure sports, which has pro- moted the popularity of leisure sports in Qingdao and created a good opportunity for Qingdao leisure sport industry. In recent years, Qingdao has gradually established its characteristic sport items and paid great efforts the development of rural leisure sports, so the happiness of Qingdao people has been increasing and Qingdao city has also become the model for many cities.

\section{THEORETICAL DEMONSTRATION OF ECO- LOGICAL CHAIN AND INDUSTRIAL CHAIN COU- PLING ON RURAL LEISURE SPORT DEVELOP- MENT}

\subsection{Assumption of Relevant Variables}

To further empirically examine the drawing effect of coupling to rural leisure sports and improvement, we select the increment of rural leisure sport industry as variable because the carrier of this dynamic effect is embodied in the increment of rural leisure sport; meanwhile select fixedasset investment and the number of employees of rural leisure sports as variables, including all the employees of other tourist industries excluding the number of employees serving state-owned and collectivity-owned tourist enterprises, and the ones from HK, Macao and Taiwan. This



Fig. (1). Long-term docking mechanism of leisure sport industry, tourism and cultural industry. 
variable is closely related with agriculture and called as agricultural variable.

\subsection{Setting, Verification and Establishment Of model}

On the basis of Cobb-Douglas production function of micro-economy, author introduced the Romer's endogenous growth theory of macro economy with consideration to both endogenous factor of external force and the influence and function of tourism on rural leisure sport. Assuming that increment of rural leisure sport is FGDP, the number of employees in the industry is $\mathrm{FE}$, production investment of current stage and previous stage is separately FFAI and FFAI $(-1)$, and the number of employees involved in agricultural tourism is SNTE, then we can establish the equation model as follow:

$$
F G D P=\theta \times F E^{\lambda_{1}} \times F F A I^{\lambda_{2}} \times F F A I(-1)^{\lambda_{3}} \times S N T E^{\lambda_{4}} .
$$

Thereinto, $\theta$ and $\lambda \mathrm{i}$ is a constant, $\mathrm{i}=1,2,3,4$; calculate the natural logarithm of both ends of equation, and obtain:

$\ln F G D P=$

$\lambda_{1} \ln F E+\lambda_{2} \ln F F A I+\lambda_{3} \ln F F A I(-1)+\lambda_{4} \ln S N T E+\varepsilon_{1}$

Formula (1) indicates the state equation of coupled first industry and tourism. For comparison, let's assume the state equation of first industry and tourism before coupling is:

$\ln F G D P=w_{1} \ln F E+w_{2} \ln F F A I+\varepsilon_{2}$

According to statistics of empirical data, carry out regression analysis on formula (1) and (2), and obtain corresponding regression equation:

$\ln F G D P=0.1503 \ln F E+0.4484 \ln F F A I+$

$0.4233 \ln$ FFAI (-1) $-0.0456 \ln S N T E$

Namely:

$\ln F G D P=0.2348 \ln F E+0.7609 \ln F F A I$

The above table shows that the data of two equation sets has the significant level of $5 \%$ and after $t$ verification on data, integral goodness of fit is above 0.901 , indicating both are highly related. Meanwhile, the DW value of two sets is close to 2 . It can be concluded that while it further gets rid of the auto-correlative problem of first-order residuals, it also further verifies the credibility and validity of regression equation in two statuses. Before coupling of both, the sum of elastic coefficients of variables of employed labor force and asset investment from the first industry gets close to 1 , which indicates that it is comparable to scale economic status. When both are coupled, the above data level exceeds 1 . Even though it displays that the scale return from the investment in labor force factor of the first industry is decreasing day by day, it cannot prove that the marginal elasticity of asset investment is not enhanced after the joint function of current effect and lagging effect. Therefore, under the coupling status of both, priority should be given to the items which require factor structural optimization, and try to reduce the investment in affluent labor forces of the first industry, enlarge the overall asset investment range, and improve the integral production efficiency of the first industry, which can embody the ever-increasing status of integral production value.

\section{IDENTIFICATION OF ECOLOGICAL AND IN- DUSTRIAL CHAIN COUPLING AND ITS EFFECT MECHANISM FOR RURAL LEISURE SPORTS}

Coupling has the features of interaction and intercoordination, and is a kind of incidence relation of dynamic interaction. In recent years, while urban population has been expanding creating greater competition pressure, the integral income of people is also increasing and people need more space and time for leisure. At present, though there are some disperse tourist programs in rural areas, such as scenic spot visit, peasant household visit and traditional festival and cultural visits, these cannot meet the more demands of new generations for leisure sports. As tourists are intended to experience the magnificent or elegant geographical conditions and natural landscapes of countryside, rural tourism should adapt to current uprising situations, innovate the thinking, expand the view and integrate handy agricultural programs to seek for more breakthroughs. However, as rural areas are somewhat isolated and hysteretic, some uprising things are difficult to extend to a large area within a short period. Therefore, attentions should be given to the inter-engagement of large-scale agriculture and rural tourism to keep providing opportunities and drives for large-scale agriculture and make the both gradually couple together forming a coupling system. In fact, system coupling is the evolutionary process to a higher level of system under the hypercycle of material,

Table 2. Verification of corresponding equations of variable of first industry increment and agricultural tourism employee number.

\begin{tabular}{|c|c|c|c|c|c|c|}
\hline & Variable & Coefficient & t-Statistical Value & Probability Level & Goodness of Fit & D-W Verification \\
\hline \hline Ecological industry & $\operatorname{lnFE}$ & 0.1503 & 3.547 & 0.0031 & 0.9079 & 1.8206 \\
\hline Coupling & LNFFAI & 0.4484 & 3.7852 & 0.0021 & & \\
\hline & $\operatorname{lnFFAI}(-1)$ & 0.4233 & 2.2247 & 0.0545 & & \\
\hline & $\operatorname{lnSNTE}$ & 0.0456 & -6.1095 & 0.0001 & 0.9127 & 1.901 \\
\hline Before coupling & $\operatorname{lnFE}$ & 0.2348 & 5.426 & 0.0001 & & \\
\hline & $\operatorname{lnFFAI}$ & 0.7609 & 15.2631 & 0 & & \\
\hline
\end{tabular}


energy and information [8-10]. Coupling itself has certain system interaction and integral coherence.

Expert analysis points out that industrial coupling is different from industrial integration. The premise of industrial integration is the integration of technology, business and market. New industrial form is embodied by penetration, crossing and recombination, but industrial coupling is different. Industrial coupling means after interest and management forms certain connection, it should further construct association and cooperation relation without changing the natural independence of original industry. Industrial coupling can not only promote industrial integration, but also can become the guarantee to integrate major parts, and keep association with sub-systems. On one hand, this function produces certain system optimization in a wider space; on the other hand, it can also improve industrial performance and value, and promote industrial innovation.

At present, people have gradually found from the view of industrial interaction that the effect of driving resource optimization and value increment of the first industry is created in ecological and industrial chain. According to part of theories of industrial integration and industrial chain, some experts have proposed that industrial interaction can to certain extent promote industrial integration and form new product. Due to the coupling of ecological and industrial chain, and the interaction between rural tourism and rural leisure sports, the consumer psychology of urban tourists have raised higher demands for rural leisure sports. Farmers have also raised wider requirements for further improvement of high value-added of rural tourism. Further optimization and adjustment of human and land resources of the first industry is required. Meanwhile, rural tourists have specific inner demands for the leisure in specific geographical environments. To improve the special effect of rural travel and leisure sport brand, it is necessary to enhance the shaping of characteristic brand and improve the integral value system of agriculture with agricultural technology.

\section{CONCLUSION}

The coupling of rural leisure sport and large-scape agriculture can not only provide agricultural foundation of dynamic value, modern service conditions, effective homogeneous participation and selection approaches required by the sustainable, profound and harmonious development of rural tourism and rural leisure sports, but also can guarantee the long-term and innovative development of rural tourism. It can be known from the above discussion that the coupling of ecological and industrial chain can form certain coupling correlation patterns which can provide reliable development approach and leading mode to help with the further development of Chinese rural leisure sport.

\section{CONFLICT OF INTEREST}

The author confirms that this article content has no conflict of interest.

\section{ACKNOWLEDGEMENTS}

This work is supported by The National Social Science Fund Project: The study of the development and the cultivation of rural leisure sports resources based on the coupling of ecological chain and Industry, Grant No : 14BTY037.

\section{REFERENCES}

[1] S. Saxena, "Problems faced by rural entrepreneurs and remedies to solve it," IOSR Journal of Business and Management (IOSRJBM), vol. 3, no. 1, pp. 23-29, 2012.

[2] K. De, S. Walter, L. M. Stephen, and F. D. Joseph, "Mad men in bib overalls: Media's horrification and pornification of rural culture," Critical Criminology, vol. 22, no. 2, pp. 179-197, 2014.

[3] R. Newbery, J. Sauer, M. Gorton, J. Phillipson, and J. Atterton, "Determinants of the performance of business associations in rural settlements in the United Kingdom: an analysis of members' satisfaction and willingness-to-pay for association survival," Environment and Planning $A$, vol. 45, no. 4, pp. 967-985, 2013.

[4] K. K. Berlin, and B. K. David, "Let me play, not exercise! a laddering study of older women's motivations for continued engagement in sports-based versus exercise-based leisure time physical activities," Journal of Leisure Research, vol. 46, no. 2, pp. 127, 2014.

[5] E. Su, Y.Q. Lin, S.L. Zhang, G.T. Leng, L.C. Lan, and H.F. Chiu, "Physical activity and cognitive function of community Chinese elderly in Hong Kong (HK) and Guangzhou (GZ)," International Psychogeriatrics, pp. 1-8, 2014.

[6] J. Li, and R. Yuhua, "On the development of leisure-oriented mass sport in yangtze delta." Advances in Electronic Commerce, Web Application and Communication, Springer, Berlin, Heidelberg, 2012, pp. 285-291.

[7] J.K. Walton, "Sport and the basques: constructed and contested identities, 1876-1936," Journal of Historical Sociology, vol. 24, no. 4, pp. 451-471, 2011.

[8] M. Recalde, and R.M. Jesús, "Going beyond energy intensity to understand the energy metabolism of nations: the case of Argentina," Energy, vol. 37, no. 1, pp. 122-132, 2012.

[9] J. H. Zhai, and J. F. Han, "Important position of information science in studying complex system," Advanced Materials Research, vol. 748, pp. 889-892, 2013.

[10] X. Guan, Z. Zhang, S. Zhang, and X. Li, "the hyper cycle evolution mechanism analysis of ecosystem of cyber-society," LISS 2013. Springer, Berlin, Heidelberg, pp. 835-840, 2015.

\footnotetext{
Received: June 10, 2015

Revised: July 29, 2015

Accepted: August 15, 2015

(C) Chenggen Peng; Licensee Bentham Open .
}

This is an open access article licensed under the terms of the (https://creativecommons.org/licenses/by/4.0/legalcode), which permits unrestricted, noncommercial use, distribution and reproduction in any medium, provided the work is properly cited. 